\title{
Combining Platelet Rich Plasma and Concentrated Bone Marrow with a Demineralized Bone Matrix Scaffold Enhances Growth Factor Release Over Time
}

\author{
J. M. Brewer ${ }^{1}$, M. B. McCarthy' ${ }^{1}$, L. Pauzenburger ${ }^{2}$, M. P. Cote ${ }^{1}$, A. D. Mazzocca ${ }^{1}$ \\ 1 Department of Orthopaedic Surgery, University of Connecticut Medical School, Farmington (CT), U.S.A. \\ 2 St. Vincent Shoulder and Sports Clinic Vienna, Vienna, Austria
}

\section{CORRESPONDING AUTHOR:}

Jennifer Brewer

University of Connecticut

Medical School

Department of Orthopaedic and Surgery

263 Farmington Ave 06034, U.S.A.

E-mail: jenbrewer830@gmail.com

DOI:

10.32098/mltj.03.2021.13

LEVEL OF EVIDENCE: N/A

\begin{abstract}
SUMMARY
Background. Scaffolds composed of demineralized bone matrix (DBM) enriched with platelet rich plasma (PRP) and concentrated bone marrow-derived mesenchymal stem cells (concentrated bMSCs) may be able to release growth factors over time. The hypothesis is that the combination of PRP + bMSCs + DBM will result in high levels of growth factor release over prolonged periods of time.

Methods. Bone morrow (BM) and whole blood was purchased from Lonza (Lonza Inc, Allendale, NJ). Whole blood was processed to give PRP. BM was concentrated, cells were counted, plated, and grown to confluence. Cells were seeded onto the DBM and augmented with (+)/(-) PRP and concentrated bMSCs. Media were collected and analyzed for BMP-2, PDGF, TGF- $\beta$ and MMP-2.

Results. bMSCs adhered to and proliferated on the DBM as well as tissue culture plastic (TCP). When PRP and concentrated bMSCs were both added to the DBM, there was significantly increased growth factor release of BMP-1, PDGF, and TGF- $\beta$. The negative control of MMP-2 showed no increased release throughout the time period measured.

Conclusions. Combining PRP and bMSCs with a DBM scaffold ensured consistently high levels of growth factor release over time. This may help to promote healing in-vivo, but remains to be proven in a clinical scenario.
\end{abstract}

\section{KEY WORDS}

Demineralized bone matrix; concentrated bone marrow derived mesenchymal cells; growth factor release; platelet rich plasma.

\section{BACKGROUND}

Tendon to bone healing of acute and chronic tendon injuries continues to be a challenge for the orthopedic surgeon, resulting in poor clinical outcomes. Tendons have a limited healing potential and surgical repair does not always yield functional outcomes (i.e. massive rotator cuff repairs). Growth factors have been shown to facilitate and regulate healing (1). Augmentation of tendon-to-bone healing with demineralized bone matrix (DBM), bone marrow (BM) and platelet rich plasma (PRP) alone have shown limited effects (2). Their limited effects could possibly be due to the concentration of PRP, BM, or that without a scaffold these materials simply wash away and do not remain at the site of injury (2). Combining all these components: DBM, BM, and
PRP may enhance healing and concentrate growth factors to the site of injury for a longer period. Scaffolds, such as DBM, create an environment that allows pro-growth factors to integrate and interact, but then the scaffold will eventually disappear (3). PRP is a source of autologous growth factors3. Combing PRP with cell based therapies such as concentrated bone marrow-derived mesenchymal stem cells (concentrated bMSCs) could potentially further enhance the release of growth factors (3). The hypothesis is that when concentrated bMSCs and PRP are added to the DBM this could promote new cell growth, increase growth factor release and promote tissue regeneration.

This study analyzed growth factors that are known to contribute to tendon to bone healing: transforming growth 
factor $\beta$ (TGF- $\beta$ ), bone morphogenetic protein 2 (BMP-2), and platelet-derived growth factor (PDGF) $(2,4)$. Transforming growth factor $\beta$ plays a role in tendon formation by cellular proliferation, differentiation, and matrix synthesis (4). Bone morphogenetic protein 2 has been shown to accelerate healing and increase the biomechanical stability of a tendon graft (2). Platelet-derived growth factor can increase collagen synthesis and enhance tendon healing (4). Matrix metalloproteinase-2 (MMP-2) was also measured and it was used as a negative control. MMP-2 is involved in the breakdown of the extracellular matrix (5).

The purpose of this study was to investigate the release of growth factors from a DBM scaffold when combined with concentrated bMSCs and PRP. The hypothesis was that when both PRP and concentrated bMSCs are present on the DBM scaffold, there will be an increased growth factor release over time compared to controls.

\section{MATERIALS AND METHODS}

The study meets ethical standards of the journal (6).

\section{Matched bone marrow and blood}

Institutional IRB approved procedures for acquiring surgical waste tissue (No. 06-577-2 for bone marrow aspirate) were used in this study. Native BM and whole blood of two male donors $(25.5 \pm 2.3$ years of age $)$ that were matched for age (23.9 and 27.1 years of age) and gender was purchased from Lonza Inc (Allendale, NJ.). This was done so that BM and PRP from the same patient could be analyzed in a more controlled environment. According to Lonza's protocol, $100 \mathrm{ml}$ 's of whole blood samples and 100 ml's fresh BM were collected and shipped from the two donors on the same day for next day delivery. Donors were in good general health according to vital signs and hematology values. Donors had a negative medical history of heart disease, kidney disease, liver disease, cancer, epilepsy, blood or bleeding disorders and test negative for HIV-1, HIV-2, hepatitis B and hepatitis C prior to every donation. For all experiments $\sim 120$ cc's of BM was concentrated and cultured according to previously described methods (7). To concentrate, the BM was separated using an automatic system (Angel, Arthrex Inc., Naples, Fl.) with a $15 \%$ hematocrit setting. This resulted in $\sim 3 \mathrm{cc}$ of product rich in nucleated and concentrated bMSCs.

For PRP, the following protocol was selected to reflect the PRP used in current clinical practice. PRP was derived using an automated system (Angel, Arthrex Inc., Naples FL) using 60 cc's of whole blood at a 7\% hematocrit setting. A complete blood count was obtained using a
Gen-S System 2 Hematology Analyzer (Coulter Corp, Miami, FL) at the institution's blood lab for platelet, red blood cells and white blood cell count differentials from a 1-ml sample of the native blood and PRP. For concentrating PRP, Leukocyte-rich PRP settings were used based on the manufacturer's recommendation. The actual number for leukocyte rich settings is not available from the manufactor.

\section{Stem cell analysis}

Prior to plating, nucleated cell number was counted and recorded (7). Nucleated cells were plated on $100 \mathrm{~mm}^{2}$ Primaria dishes (Corning, Tewksbury, MA) at a concentration of $5 \times 10^{5}$ cells $/ 9.6 \mathrm{~cm}^{2}$ phenol red free $\alpha$-minimum essential medium (ThermoFisher, Waltham, MA), $10 \%$ fetal bovine serum (ThermoFisher), and $0.1 \%$ penicillin/ streptomycin (ThermoFisher). After 7-10 days, non-adherent cells were removed, and colony-forming units (CFU) were counted. bMSCs were grown to confluence and expanded. Only first passage cells were used for experimentation. Morphological analysis was performed using phase-contrast microscopy with a Nikon Eclipse TS 100 Microscope (Nikon Instruments, Melville, NY). Stem cells were then defined by their 1) adhesion to tissue culture plastic (TCP) 2) colony-forming potential, 3) ability to differentiate into tendon, cartilage, bone and fat tissue; and 4) fluorescence-activated cell sorting (FACS) analysis for surface markers (7-12).

\section{FACS analysis}

Fluorescence-activated cell sorting (FACS) was used to ensure that cells obtained had surface markers characteristic of stem cells. bMSCs were trypsinized in $0.25 \%$ trypsin/ EDTA at confluence, rinsed, and centrifuged. The pellet was re-suspended in staining buffer containing $1 \%$ human serum, $1 \%$ bovine serum albumin, and $1 \%$ fetal bovine serum in phosphate-buffered saline. Cells were incubated with either phycoerythrin or fluorescein isothiocyanate antibodies, washed with staining buffer, and analyzed using a FACS Calibur (BD Biosciences, San Jose, CA). To identify bMSCs the phycoerythrin-conjugated mouse monoclonal anti-CD73 immunoglobulin $\mathrm{G}(\mathrm{IgG})$, anti-CD90 $\operatorname{IgG}$, anti-CD105 and fluorescein isothiocyanate-conjugated anti-mouse CD45 monoclonal IgG were obtained from $\mathrm{BD}$ Biosciences. These were chosen in correlation with the suggestions of the International Society for Cell Therapy (8). All antibodies were reactive against human antigens. Testing with negative and positive controls confirmed the specificity of these antibodies. 


\section{Biologic scaffold}

A sterile DBM scaffold (Flexigraft, Arthrex, Naples, FL) was chosen for this study, which allows for PRP and concentrated bMSCs to remain in place to augment growth factors remaining at the site of injury to enhance healing over a longer period of time. Prior to experimentation, bMSC adhesion, proliferation and viability on the scaffold was tested. The sterile scaffold was cut into $5 \times 5 \mathrm{~mm}$ pieces and each piece was placed into one well of a 24-well Falcon Primaria cell culture dish (Corning, Tewksbury, MA) prior to testing.

\section{Cell adhesion and proliferation assays}

bMSCs from each donor at a concentration of 250,000 cells/0.1 ml were pipetted onto the DBM scaffold. DBM alone (minus cells) and TCP (gold standard) were used as controls. Prior to the addition of media to the well, cells were allowed to adhere to each scaffold for 60 minutes. For the adhesion assay, scaffolds were removed from the well after a 24 hours incubation period. The adherent cells were removed from the sample by incubating with $0.5 \mathrm{ml}$ trypsin for 20 minutes at $37^{\circ} \mathrm{C}$. The cells from each sample were counted 3 times each in a Coulter counter (Coulter Electronics, Hialeah, FL) (12).

For the proliferation assay, cells were labeled with $5 \mathrm{Ci} /$ $\mathrm{ml}$ of tritium-labeled $([3 \mathrm{H}])$ thymidine (NEN, Boston, MA) which incorporates and binds to nuclear DNA, after culturing the scaffold samples for 24 hours. After 48 hours, the samples were removed and washed twice for 5 minutes with $10 \%$ trichloroacetic acid to remove insoluble $[3 \mathrm{H}]$-thymidine. Cells were lysed for 10 minutes in $0.5 \mathrm{~N}$ sodium hydroxide. The radioactive thymidine was incorporated into the DNA of dividing cells, and therefore an increase in radioactivity above the negative control directly correlates to cellular proliferation (13). Radioactivity was measured in the lysates with a liquid scintillation counter (Packard Instrument, Downers Grove, IL) and was repeated three times for consistency $(12,13)$.

\section{Live/dead assay}

After 7 and 14 days of cell culture each sample was stained with $2 \mu \mathrm{M}$ calcein-AM and $4 \mu \mathrm{M}$ Ethidium homodimer-1 in sterile PBS for 30 minutes (Invitrogen, Molecular Probes, Eugene, OR). Samples were placed on glass slides and examined for cell viability using a Leica DMI 6000B microscope (Leica Microsystems, Buffalo Grove, IL). Viable cells stained green while dead cells stained red.

\section{Experimental design}

After concentrated bMSCs were characterized as stem cells and cells positively attached to and proliferated on the scaffold material, growth factor release was studied. Concentrated bMSCs, PRP or a combination of concentrated bMSCs and PRP was added to each scaffold in a $100 \mu \mathrm{L}$ volume (figure 1) and allowed to incubate for 60 minutes to ensure adhesion, as most cells adhere to a substrate through integrin receptors in less than 30 minutes (14). At the end of 60 minutes, $1 \mathrm{ml}$ of complete cell culture media (phenol free alpha-MEM, $10 \%$ fetal bovine serum, and $0.1 \%$ penicillin), and 10\% bovine thrombin (Sigma-Aldrich Corp., St. Louis, MO, USA).

Cell media was added to each well to ensure a clot formed around the substrate. Control wells consisted of DBM and culture media or PRP only. Samples were incubated at 37 ${ }^{\circ} \mathrm{C}$ in $5 \% \mathrm{CO}_{2}$ for $0,24,48,72 \mathrm{hrs}$. and 7, 14 and 21 days. 21 days was chosen as a final time point because after three weeks in culture the cells would over populate the DBM and cells would begin to die.

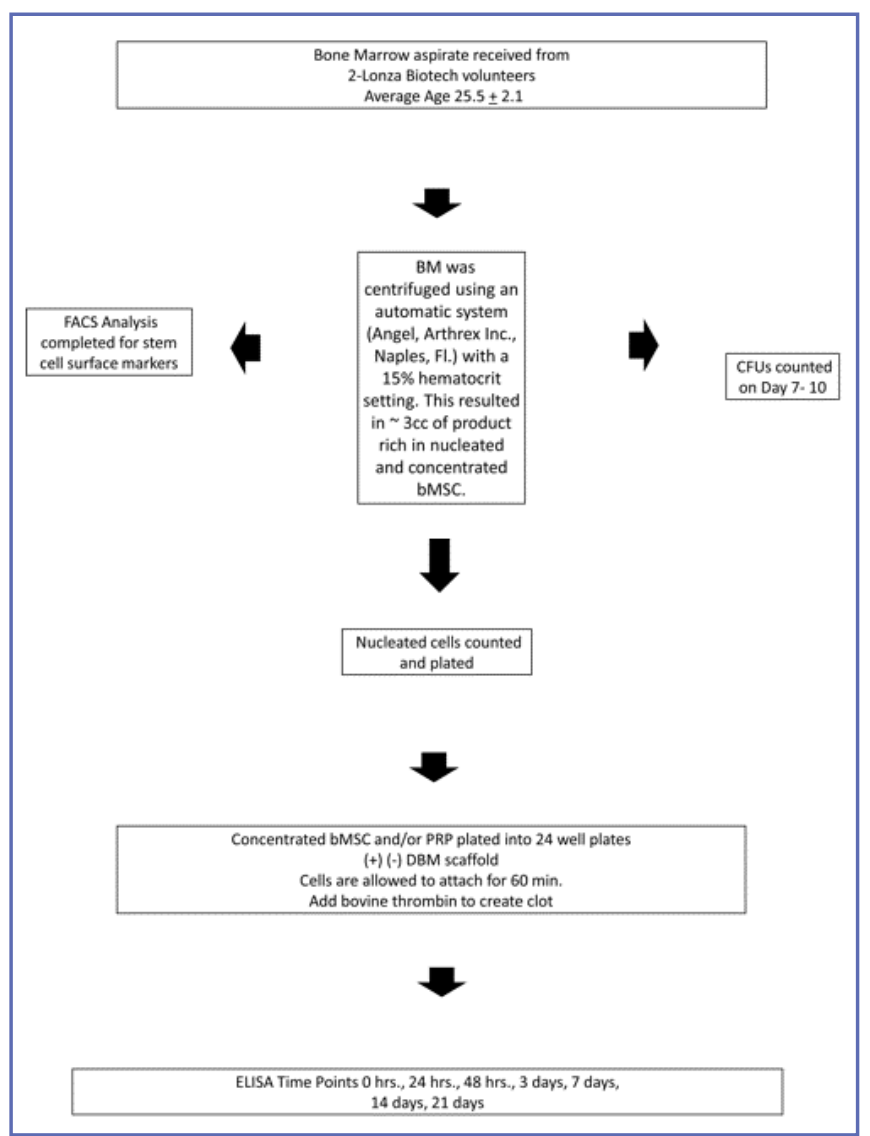

Figure 1. Schematic of study design and groups. FACS, fluorescence activated cell sorting; CFU, colony forming units; DBM, decellularized bone matrix; PRP.

Muscles, Ligaments and Tendons Journal 2021;11 (3) 


\section{Assessment of growth factors}

Media of each time point was collected and analyzed for BMP-2, PDGF, TGF-B, and MMP-2 by ELISA (abcam, Cambridge, MA) according to the manufacturer's protocol. At the end of each time point, media only, not scaffold material, was collected by pipette and saved for analysis so that for each time point a cumulative amount of growth factors was measured. No media was replaced into the well as only a small amount was taken. Each of the six conditions was repeated twice with two donors, creating an $\mathrm{n}=4$ for each growth factor's time point, totaling 168 wells per growth factor with six time points, for a sum of 672 wells tested.

\section{Statistics}

Descriptive statistics including mean and standard deviation was calculated to characterize the study conditions. Differences in growth factor release between the conditions at each time point was evaluated with the Kruskal Wallis test. When significant pairwise comparisons were carried out using Dunn's test of multiple comparisons. Differences in growth factor release across time points within each condition were evaluated with the Friedman test. When significant pairwise comparisons were carried out using the Wilcoxon signed-ranks test. A p value less than 0.05 was considered statistically significant. All analysis were conducted with Stata 15 software (StataCorp. 2017. Stata Statistical Software: Release 15. College Station, TX: StataCorp LLC).

\section{RESULTS}

\section{Matched bone marrow and blood}

An average total leukocyte concentration of $10.01 \pm 0.10$ x $10^{3}$ cells $/ \mu \mathrm{L}$ and an average platelet concentration of $2128.67 \pm 0.34 \times 10^{3}$ cells $/ \mu \mathrm{L}$ was found for the two donors. On day 10 , colonies were counted resulting in $27.23+15.9$ colony forming units (CFU) $/ 10^{6}$ nucleated cells and $2067+$ $1289 \mathrm{bMSCs} / \mathrm{ml}$ of concentrated BM.

\section{Stem cell analysis}

Before their use in this study, bMSCs were successfully differentiated into cartilage, bone, tendon, and fat cells. After adhering to TCP and the formation of colony forming units (figure $2 \mathrm{~A}, \mathrm{~B}$ ), bMSCs displayed typical fibroblast morphological characteristics with a fusiform shape after becoming confluent (figure 2 c).

\section{FACS analysis}

FACS analysis (figure 3 ) results revealed a high percentage of CD73 (98.4 $\pm 0.4 \%)$, CD90 (98.6 $\pm 0.25 \%)$, and CD105 $(98.8+0.5 \%)$ surface markers and a minimal amount of CD45 surface marker $(0.51 \pm 1.1 \%)$, used as the negative control.

Combined, these results show that the cells used in this study were pluripotent in nature and displayed characteristics of stem cells (7-11).

\section{Cell adhesion and proliferation assays}

Prior to analysis, all data was normalized to one another according to surface area. Figure 4 A, B show the number of cells that adhered to and proliferated on the DBM scaffold after 24 or 48 hours in culture. There were no significant differences in the number of cells that attached to or proliferated on the DBM when compared to control TCP $(\mathrm{p}=0.414$ and $\mathrm{p}=0.314)$.

\section{Live/dead assay}

The live/dead assay was performed after 7 and 14 days of cell incubation on the scaffold. Figure 5 A, B shows representative images of the results of the live/dead assay. After 7

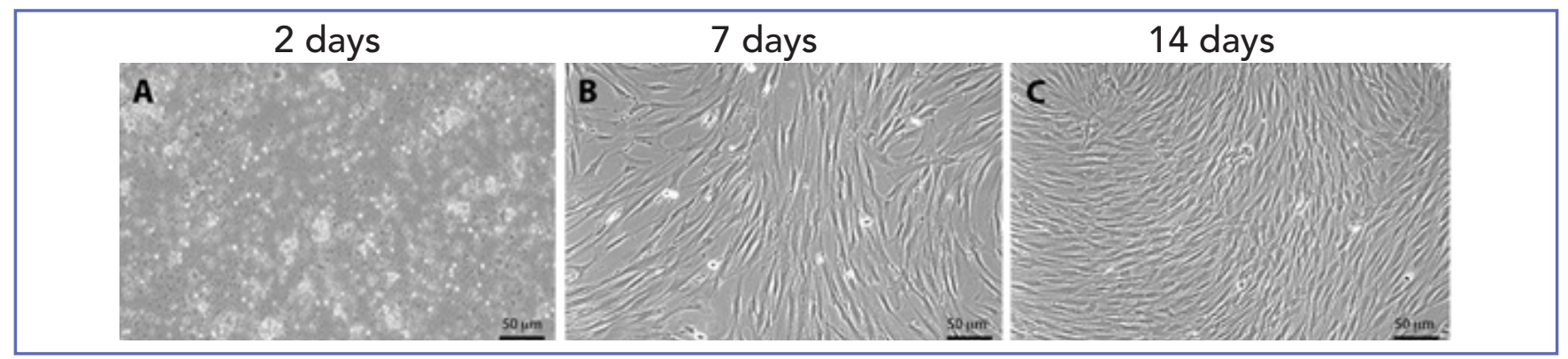

Figure 2 A-C. Morphological features of concentrated bone marrow-derived mesenchymal stem cells (bMSCs). The concentrated bMSCs displayed the ability to attached to TCP and form colonies after 2 days in culture (A). By 7 days, bMSCs showed a typical fibroblast-like morphology with a fusiform shape. 10X magnification. 


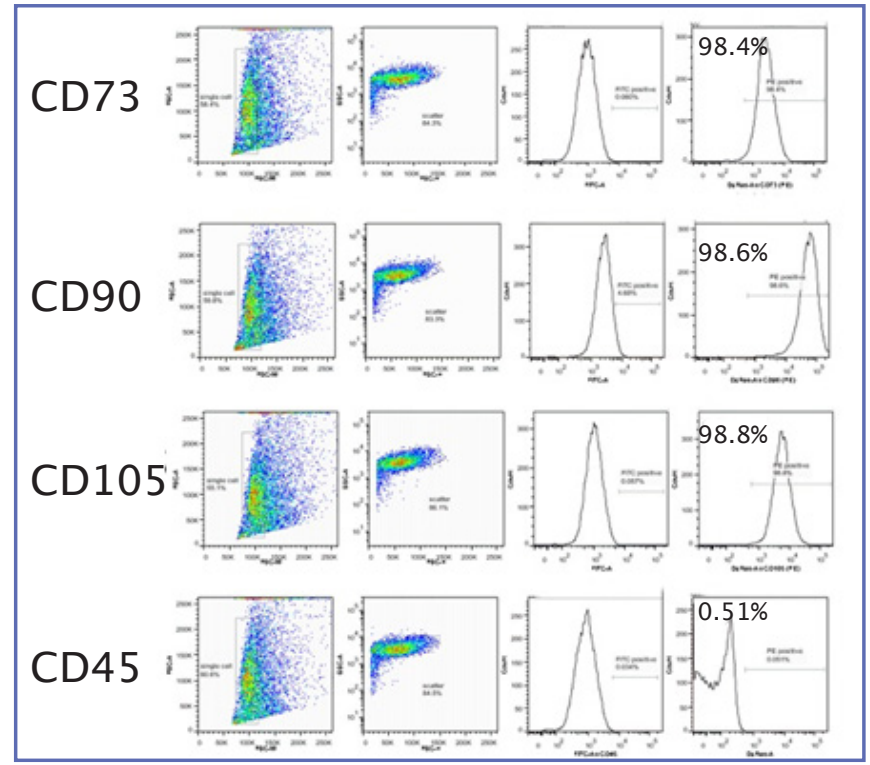

Figure 3. FACS analyss showed that bMSCs were positive for CD73, CD90 and CD105 and simultaneously negative for CD45 in addition to their potential to form colonies, differentiate into different cell lines and adhere to tissure culture plastic, all indicative of adult bMSCs.

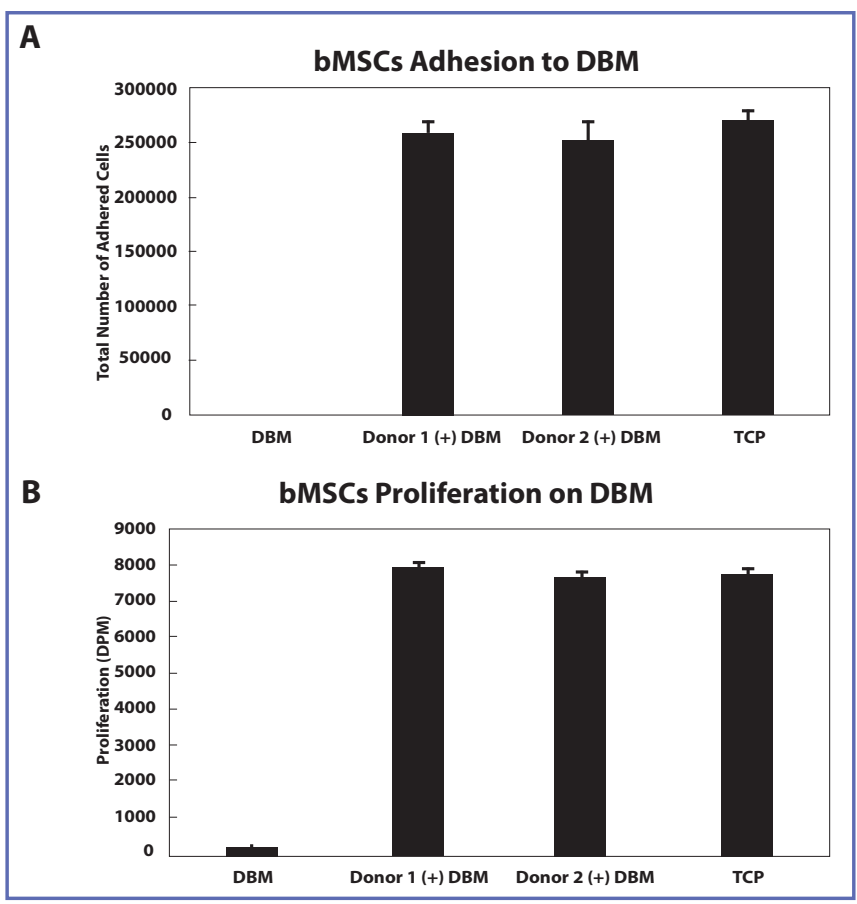

Figure 4 ( $\mathrm{A}, \mathrm{B})$. Adhesion and proliferation results of bMSCs after 24 and 48 hours in culture on the DBM scaffold. After normalization for surface area to the TCP, there were no significant differences seen in adhesion or proliferation between either donor and the TCP.
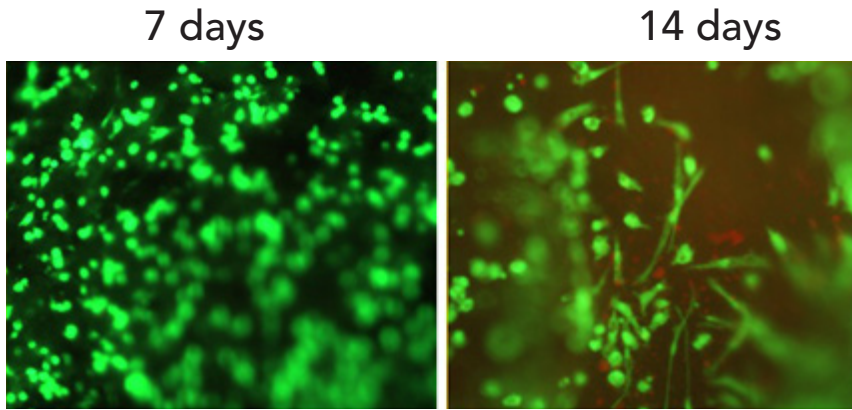

Figure 5. Fluorescent microscopy images of the live/dead assay show healthy cells after 7 and 14 days in culture on the DBM scaffold. Colonies began to form after 7 days in culture with the cells taking on a typical stem cell morphology with spinal like processes after 14 days. $10 \mathrm{X}$ magnification.

days in culture cell still appeared rounded, and CFU's could be seen forming on the scaffold surface. By 14 days, bMSCs began to expand and spindle like processes were noted. Healthy cells were stained green, while dead or dying cells were stained red.

\section{Growth factor expression \\ TGF- $\beta$}

Results of TGF- $\beta$ growth factor release showing significantly greater release in the DBM + PRP + concentrated bMSCs as compared to PRP and concentrated bMSCs alone at twenty-four hours as well as at three days ( $\mathrm{p}$ $=.02, \mathrm{p}=.0007, \mathrm{p}=.04, \mathrm{p}=.0007, \mathrm{p}=.05, \mathrm{p}=.001)$. $\mathrm{DBM}+\mathrm{PRP}+$ concentrated bMSCs did not have significantly increased release at three, seven and fourteen days as compared to PRP, fourteen, and twenty-one days ( $p$ $=.054, \mathrm{p}=.211, \mathrm{p}=.211$ ). There was significantly less TGF- $\beta$ release in DBM+concentrated bMSCs compared to DBM+PRP only at seven days $(p=.04)$. PRP alone had significantly increased TGF- $\beta$ release compared to PRP alone at 14 and 21 days and DBM+concentrated bMSCs at 21 days $(\mathrm{p}=.008, \mathrm{p}=.032, \mathrm{p}=.015)$. The scaffold alone has some TGF- $\beta$ release, even though it was less than the other conditions for time points 0 to 21 -days (figure 6 ).

\section{PDGF}

PDGF expression was significantly greater in the $\mathrm{DBM}+\mathrm{PRP}+$ concentrated bMSCs group compared to PRP and concentrated bMSCs alone at twenty-four hours, three, seven, and fourteen days $(\mathrm{p}=.02, \mathrm{p}=.008$, $\mathrm{p}=.002, \mathrm{p}=.05, \mathrm{p}=.03, \mathrm{p}=.007, \mathrm{p}=.05, \mathrm{p}=.0007)$. There was significantly less PDGF expression in the concentrated bMSCs compared to DBM+PRP at 24 hours, 


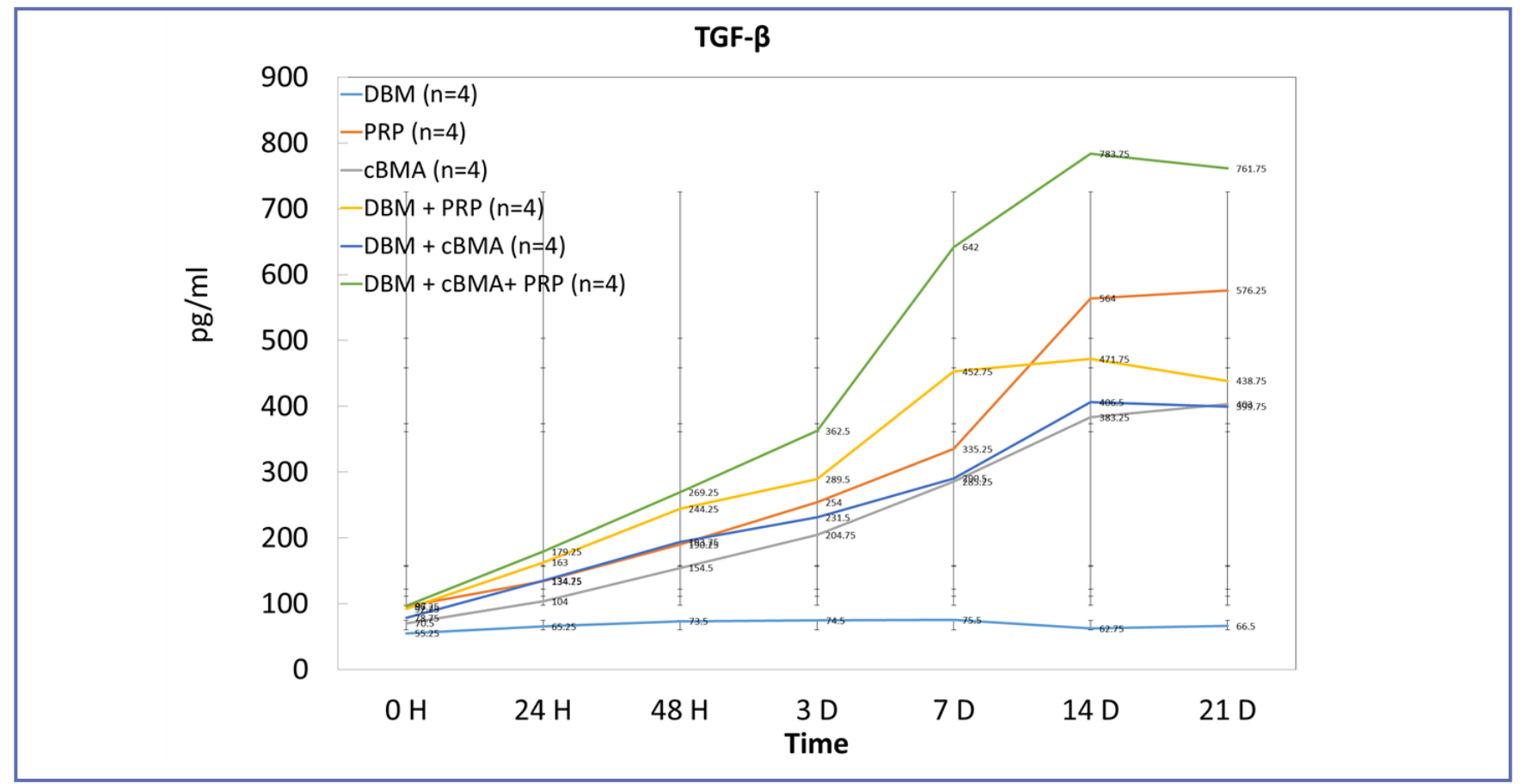

Figure 6. TGF- $\beta$.

Results of TGF- $\beta$ growth factor showing significantly greater release with concentrated bMSC and PRP on DBM as compared to PRP and concentrated bMSC alone at twenty-four and forty eight hours as well as at three, seven, fourteen, and twenty-one days. PRP alone, without the DBM scaffold had increased TGF- $\beta$ release than PRP or concentrated bMSC with the DBM at fourteen and twenty-one days. Concentrated bMSC alone had increased TGF- $\beta$ release over time, but still had less release of TGF- $\beta$ than DBM with PRP, concentrated bMSC or DBM with PRP and concentrated bMSC at twenty-four, forty eight hours, three, and fourteen days. The scaffold alone has some TGF- $\beta$ release, even though it was less than the other conditions for time points 0 to 21 days. Error bars represent standard error.

seven, fourteen, and twenty-one days $(\mathrm{p}=.05, \mathrm{p}=.05, \mathrm{p}=$ $.008, \mathrm{p}=.001)$. DBM alone had some PDGF expression, but it did not increase over time. After fourteen day, PRP alone had increased PDGF release compared to concentrated bMSCs alone $(p=.05)$, however this was not significantly different at other time points (figure 7).

\section{BMP-2}

BMP-2 had significantly greater expression on the $\mathrm{DBM}+\mathrm{PRP}+$ concentrated bMSCs group compared to PRP and concentrated bMSCs alone at three, seven, fourteen, and twenty-one days $(\mathrm{p}=.008, \mathrm{p}=.0001, \mathrm{p}=.0047$, $\mathrm{p}=.0013, \mathrm{p}=.008, \mathrm{p}=.0007, \mathrm{p}=.008, \mathrm{p}=.0007)$. There was significantly less BMP-2 released in the PRP group compared to DBM+concentrated bMSCs at three, seven, fourteen, and twenty-one days $(\mathrm{p}=.01, \mathrm{p}=.05, \mathrm{p}=.04$, $\mathrm{p}=.05, \mathrm{p}=.05)$. DBM alone had some BMP-2 release, although it was significantly less than the other groups at seven, fourteen and twenty-one days (figure 8).

\section{MMP-2}

There was very little increase release of MMP-2 throughout the time period. PRP alone was found to have significant differences in expression of MMP compared to concentrated bMSCs, $\mathrm{DBM}+\mathrm{PRP}, \mathrm{DBM}+$ concentrated bMSCs at 24 hours, 3, 7, 14 and 21 days $(\mathrm{p}<.05)$. There was no difference in the release of MMP-2 in the conditions studied by 21-days (figure 9).

\section{DISCUSSION}

There was no significant difference seen in adhesion or proliferation between either donor or the TCP. This demonstrates the cells from the two donors did not differ in adhesion or proliferation.

The live dead assay showed healthy cells after 7 and 14 days in culture on the DBM scaffold. This demonstrates cells remained healthy on the DBM scaffold after 14 days.

This study found that combining DBM + PRP + concentrated bMSCs was able to increase growth factor release 


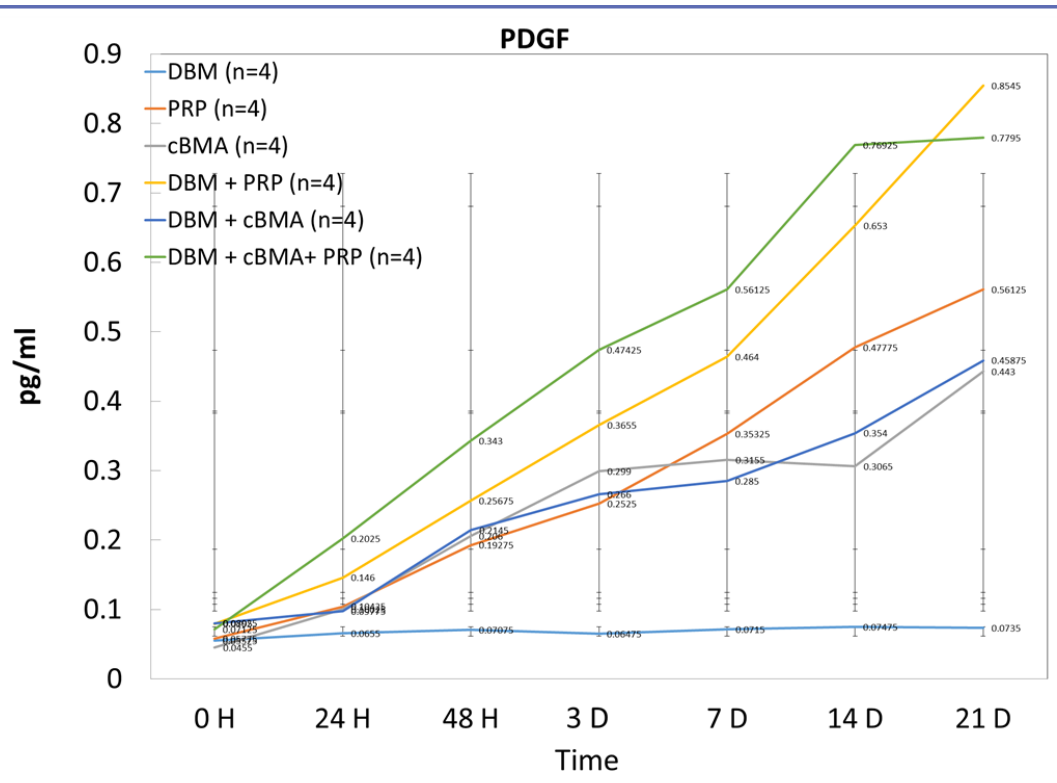

Figure 7. PDGF data.

Results of PDGF expression showing significantly greater release on DBM scaffold with both concentrated bMSC and PRP compared to PRP and concentrated bMSC alone at twenty-four, forty-eight hours, three, seven, and fourteen. There was significantly less PDGF release in concentrated bMSC compared to PRP when placed on the DBM scaffold at 24 and 48 hours, three, seven, fourteen, and twenty-one days. DBM alone had some PDGF release, but it did not increase over time. PRP alone had increased PDGF release compared to concentrated bMSC alone and DBM with concentrated bMSC at seven, fourteen, and twenty-one days. Error bars represent standard error.

\section{BMP-2}

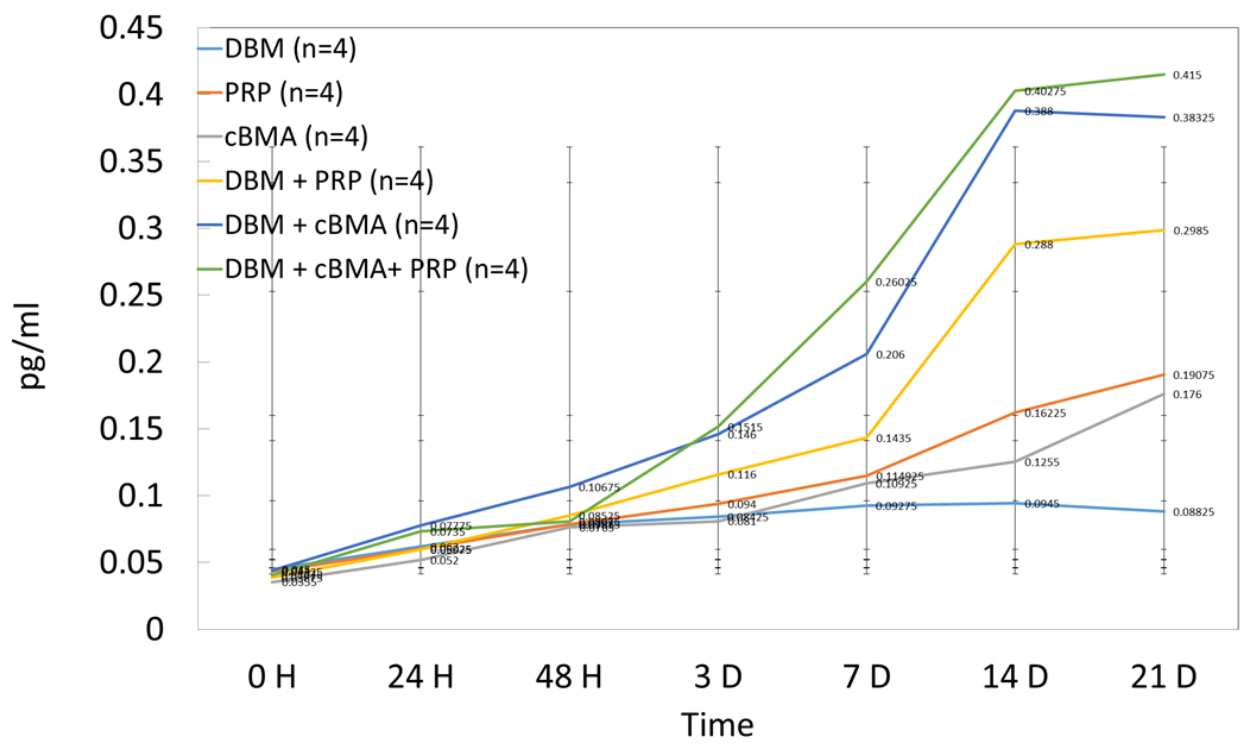

Figure 8. BMP-2 data.

Results of BMP-2 release showing significantly greater expression on DBM scaffold with both concentrated bMSC and PRP compared to PRP and concentrated bMSC alone at three, seven, fourteen, and twenty-one days. As well, at forty-eight hours concentrated bMSC had the greatest BMP-2 release when placed on the scaffold compared to all other groups. DBM alone had some BMP-2 release, although it was less than the other groups at seven, fourteen and twenty one days. PRP alone had increased BMP-2 release compared to concentrated bMSC or the DBM scaffold alone at fourteen and twenty-one days. Error bars represent standard error. 


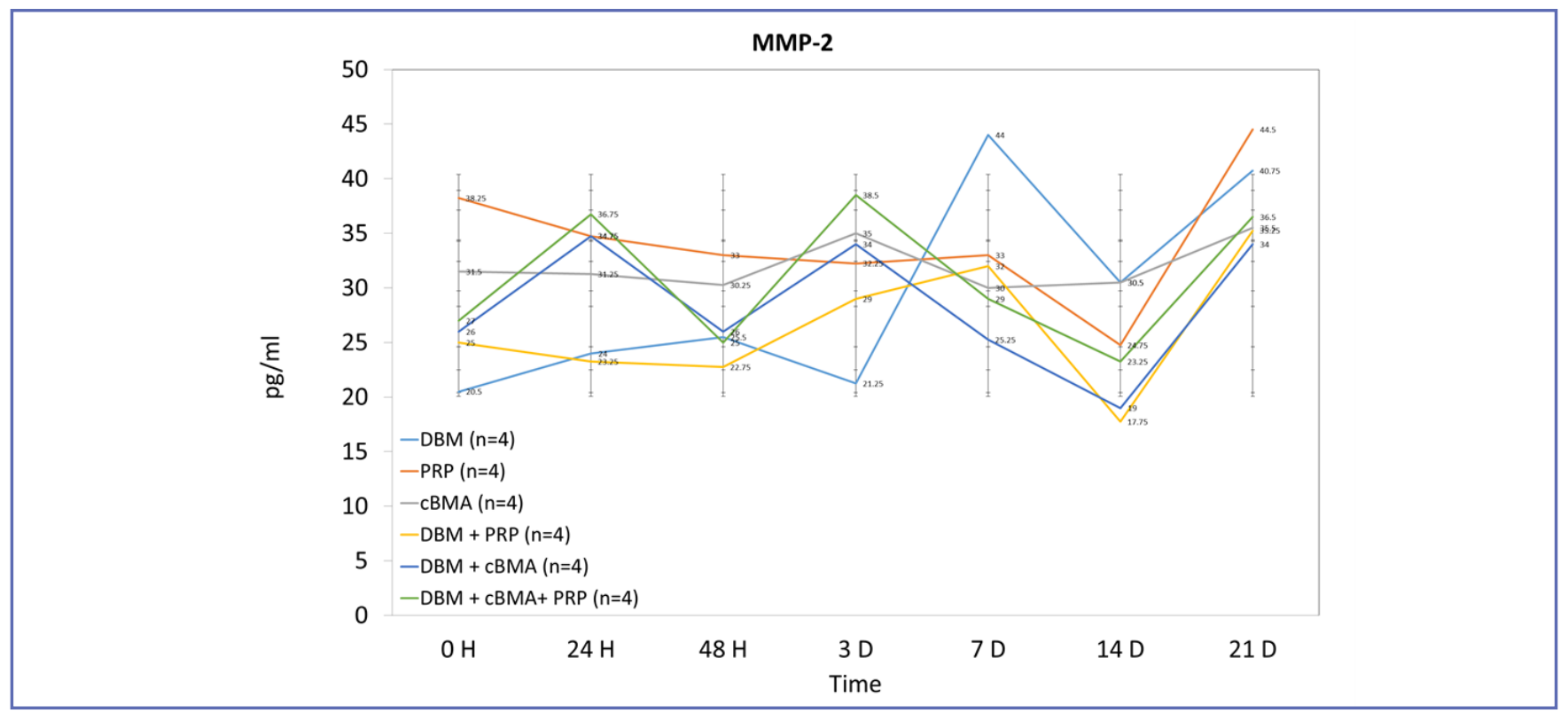

Figure 9. MMP-2 data.

Results of MMP-2 release. There was no difference in the release of MMP-2 in the conditions studied by 21 days. DBM alone had MMP-2 release and had the highest release at seven days compared to all other conditions studied. Error bars represent standard error.

over time. Although it was not significant, this study found similar results that there was growth factor release with the DBM scaffold alone with no addition of growth factors. Similarly, there was increased release of growth factors over time with the DBM+PRP. It is expected that growth factors release quickly from the DBM, especially since the growth factors used have relatively short half-lives. Per the study design, at each time point media was collected and an ELISA run. Therefore, growth factors remaining within the scaffold were not measured, just the growth factors in the media that have been released from the scaffold, or ultimately released into the in-vivo environment. Once the DBM is placed in the in-vitro environment, the growth factors seem to be adhering to the DBM and are released over time rather than all at once.

PRP alone showed increased TGF- $\beta$ more so than DBM + PRP and DBM + concentrated bMSCs. This finding could be due to intrinsic properties of the PRP. To create PRP products, human blood is spun down to its residual components to produce plasma that is platelet rich. Leukocyte rich PRP was created and platelet, leukocyte, and red blood cell numbers were controlled for. Higher leukocyte PRP has been found to be a source of cytokines and enzymes that are beneficial for healing and help drive certain molecules into the area of the injured tissue such as TGF- $\beta$, one of the growth factors we directly measured (15). The current results suggest there are interactions occurring when DBM
+ PRP + concentrated bMSCs are combined that are causing growth factors to be released consistently over time.

Strengths of the present study include the large number of total wells used and the presence of clear, significant increases in growth factor release over time when DBM + PRP + concentrated bMSCs were combined. Weaknesses of the study include the following: Although the number of cells was controlled for in each well by maintaining the average number of leukocyte concentration at day 0 , there is no way to know if after twenty-one days the same number of cells were maintained at the site. This study also used an in-vitro model of DBM + PRP + concentrated bMSCs, which does not fully capture all the factors involved in growth factor release in-vivo. Concentrated bMSCs were obtained from volunteer patients. Although their average age is known and it can be presumed they are healthy, growth factor levels in PRP have been found to correlate with donor age, sex, and platelet number, therefore, PRP products from two donors can vary (16). Using two donors is a limitation, but two donors were used because matching the concentrated bMSCs and whole blood was cost prohibitive.

The results of this study complemented previous studies, which showed increased concentrations of growth factors and cytokines when both PRP and concentrated bMSCs were present $(17,18)$. Other studies have found PRP alone can enhance cellular activity in-vitro, however, the overall efficacy of PRP for clinical use is yet to be determined 
(19). As previously mentioned DBM alone has been found to release growth factors $(20,21)$. To date, no other studies measured the release of growth factors over time with DBM or concentrated bMSCs alone. Several studies have found that PRP alone provides increased expression of growth factors over time, in fact the growth factor release has been measured up to 21-days (22-24). Previous studies have compared DBM and a fibrin scaffold when combined with PRP and concentrated bMSCs and found DBM as the favorable scaffold (25). In the current study, this knowledge was expanded upon by demonstrating that the DBM can be used as a cell carrier for PRP and concentrated bMSCs to enhance expression of growth factors that can potentially promote tendon to bone healing over time.

\section{REFERENCES}

1. Maffulli N, Longo UG, Loppini M, Berton A, Spiezia F, Denaro $V$. Tissue engineering for rotator cuff repair: An evidencebased systematic review. Stem Cells Int 2012;2012:42-6. Doi:10.1155/2012/418086.

2. Lorbach O, Baums MH, Kostuj T, et al. Advances in biology and mechanics of rotator cuff repair. Knee Surgery, Sport Traumatol Arthrosc 2015;23(2):530-41. Doi:10.1007/s00167014-3487-2.

3. Oryan A, Alidadi S, Moshiri A, Maffulli N. Bone regenerative medicine: Classic options, novel strategies, and future directions. J Orthop Surg Res 2014;9(1):1-27. Doi:10.1186/1749-799X-9-18.

4. Würgler-Hauri CC1, Dourte LM, Baradet TC, Williams GR SL. Temporal expression of 8 growth factors in tendon-to-bone healing in a rat supraspinatus model. J Shoulder Elb Surg 2014;16(5):S198-203. Doi:10.1016/j. jse.2007.04.003.Temporal.

5. Lozito TP, Tuan RS. Mesenchymal stem cells inhibit both endogenous and exogenous MMPs via secreted TIMPs. J Cell Physiol 2011;226(2):385-96. Doi:10.1002/jcp.22344.

6. Padulo J, Oliva F, Frizziero A MN. Basic principles and recommendations in clinical and field Science Research: 2016 Update. Mus Lig Tend J 2016;6(1):1-5.

7. Mazzocca AD, McCarthy MBR, Chowaniec DM, Cote MP, Arciero RA, Drissi H. Rapid Isolation of Human Stem Cells (Connective TissueProgenitorCells) From theProximalHumerus During Arthroscopic Rotator Cuff Surgery. Am J Sports Med 2010;38(7):1438-47. Doi:10.1177/0363546509360924.

8. Dominici M, Le Blanc K, Mueller I, et al. Minimal criteria for defining multipotent mesenchymal stromal cells. The International Society for Cellular Therapy position statement. Cytotherapy 2006;8(4):315-7. Doi:10.1080/14653240600855905.

9. Muschler GF, Nitto H, Boehm CA EK. Age and gender related changes in cellularity of human bone marrow and the prevalence of osteolastic progenitors. J Orthop Res 2001;19(1):117-25.

10. Nishida S, Endo N, Yamagiwa H, Tanizawa T T, HE. Number of Osteoprogenitor Cells in Human Bone Marrow Marked-
Combining PRP and concentrated bMSCs with a DBM scaffold ensured consistently high levels of growth factor release over time in an in-vitro model. This can be applied clinically in that allowing for these factors to be released over time in a concentrated area could allow for better healing of tendons $(26,27)$. However, further studies are necessary to investigate if the combination of PRP, concentrated bMSCs, and a DBM scaffold can improve healing in-vivo.

\section{CONFLICT OF INTERESTS}

The research conducted in this lab is in part funded by Arthrex, otherwise there are no other relationships/conditions/circumstances that present potential conflicts of interests.

ly Decreases After Skeletal Maturation. J Bone Min Metab 1999;17(3):171-7.

11. Chamberlain G, Fox J, Ashton B MJ. Concise Review: mesenchymal stem cells: their phenotype, differentiation capacity, immunological features, and potential for homing. Stem Cells 2007;25(11):2739-49.

12. Shea KP, McCarthy MB, Ledgard F, Arciero C, Chowaniec D MA. Human Tendon Cell Response to 7 Commerically Available Extracellular Matrix Materials: An In Vitro Study. Arthroscopy 2010;26(9):1181-8.

13. NG KW, Leong DT, Hutmacher D. The challenge to Measure Cell Proliferation in Two and Three Dimensions. Tissue Eng 2005;11(1-2):182-91.

14. Noble Paul, Liang Jiurong JD. Augmentation of integrin-mediated mechanotransduction by hyaluronic acid. Physiol Rev 2011;91(1):221-64. Doi:10.1016/j.biomaterials.2013.09.066. Augmentation.

15. Zavadil DP, Satterlee CC, Coastigan JM, Holt DW, Shostrom VK. Autologous Platelet Gel and PPP reduce pain with total shoulder arthroplasty. J Extra Corpor Technol 2007;39(3):177-82.

16. Weibrich G, Kleis WKG, Hafner G, Hitzler WE, Wagner W. Comparison of platelet, leukocyte, and growth factor levels in point-of-care platelet-enriched plasma, prepared using a modified Curasan kit, with preparations received from a local blood bank. Clin Oral Implants Res 2003;14(3):357-62. Doi:10.1034/ j.1600-0501.2003.00810.x.

17. Mishra A, Tummala P, King A, et al. Buffered platelet-rich plasma enhances mesenchymal stem cell proliferation and chondrogenic differentiation. Tissue Eng Part C Methods 2009;15(3):431-5. Doi:10.1089/ten.tec.2008.0534.

18. Vogel JP, Szalay K, Geiger F, Kramer M, Richter W, Kasten P. Platelet-rich plasma improves expansion of human mesenchymal stem cells and retains differentiation capacity and in vivo bone formation in calcium phosphate ceramics. Platelets 2006;17(7):462-9. Doi:10.1080/09537100600758867.

19. D'Elia CO, de Rezende MU, Bitar AC, et al. Comparison between platelet-rich plasma and autologous iliac 
grafts for tibial osteotomy. Cartilage 2010;1(4):320-7. Doi:10.1177/1947603510376820.

20. Wildermann, Kadow-Romacer, Haas S. Quantification of various growth factors in different demineralized none matrix preparations. J Biomed Mater Res A 2006;81(2):437-2.

21. Han B, Tang B, Nimni ME. Quantitative and sensitive in vitro assay for osteoinductive activity of demineralized bone matrix. J Orthop Res 2003;21(4):648-54. Doi:10.1016/S07360266(03)00005-6.

22. Dohan Ehrenfest DM, Rasmusson L, Albrektsson T. Classification of platelet concentrates: from pure platelet-rich plasma (P-PRP) to leucocyte- and platelet-rich fibrin (L-PRF). Trends Biotechnol 2009;27(3):158-67. Doi:10.1016/j. tibtech.2008.11.009.
23. McCarrel T, Fortier L. Temporal growth factor release from platelet-rich plasma, trehalose lyophilized platelets, and bone marrow aspirate and their effect on tendon and ligament gene expression. J Orthop Res 2009;27(8):1033-42. Doi:10.1002/ jor.20853.

24. Tsay RC, Vo J, Burke A, Eisig SB, Lu HH, Landesberg R. Differential growth factor retention by platelet-rich plasma composites. J Oral Maxillofac Surg 2005;63(4):521-8. Doi:10.1016/j.joms.2004.09.012.

25. Hoberman AR, Cirino C, McCarthy MB, et al. Bone Marrow-Derived Mesenchymal Stromal Cells Enhanced by Platelet-Rich Plasma Maintain Adhesion to Scaffolds in Arthroscopic Simulation. Arthroscopy 2017;34(3):872-81. Doi:10.1016/j.arthro.2017.08.291. 